\title{
Mental Health Disparities Among Low-Income US Hispanic Residents of a US-Mexico Border Colonia
}

\author{
Guadalupe Marquez-Velarde • Sara Grineski • \\ Kathleen Staudt
}

Received: 14 September 2014 / Revised: 21 January 2015 / Accepted: 16 February 2015 /Published online: 12 March 2015

(C) W. Montague Cobb-NMA Health Institute 2015

\begin{abstract}
Unregulated residential settlements along the US side of the US-Mexico border, often called "colonias", are mainly populated by low-income Mexican-origin Hispanics. Colonia residents face numerous social, environmental, economic and public health challenges. Despite this, the mental health of individuals living in colonias has remained largely understudied. Drawing from a survey $(N=98)$ conducted through a community-based participatory research project in one colonia suffering from numerous environmental and social challenges, this study analyzes residents' mental health outcomes and access to mental health care with a focus on intraethnic disparities based on environmental concerns, nativity, language acculturation, comorbidity, gender, health insurance, and stressful life events. Data were analyzed using descriptive statistics, correlation, and regression. More than one third of the residents have been diagnosed with a mental health condition and over half reported stress and excess worry. In terms of mental health care, $77 \%$ of individuals diagnosed with a mental health problem have sought additional help mainly through a primary care provider despite the high levels of uninsured individuals. Comorbidity, being female, recent negative life events, and high levels of environmental concerns were significant predictors of negative mental health outcomes. This study contributes to the understanding of the complex health dynamics of the US Hispanic population. It also highlights the need for additional research and resources devoted to the mental health of low-income minorities in isolated communities.
\end{abstract}

Keywords Mental health $\cdot$ Colonia $\cdot$ Hispanic · Environmental concerns $\cdot$ Mental health care . US-Mexico border

G. Marquez-Velarde $(\square) \cdot$ S. Grineski $\cdot$ K. Staudt Texas A\&M University, College Station, TX, USA e-mail: gmarquez6@tamu.edu

\section{Introduction}

Colonias are unincorporated and unregulated peri-urban settlements along the United States-Mexico border that are home to primarily Mexican-origin populations [1]. Colonia residents face unique health challenges due to poverty, lack of access to health care, inadequate infrastructure, and environmental threats. The physical health of colonia residents has been previously examined and researchers have documented significant public health challenges [2-4]. In spite of this, the mental health of colonia residents remains largely understudied. Westway, the site of this study of mental health, is a colonia ${ }^{1}$ in El Paso County (Texas). In this county in 2010, 86,472 residents lived in 321 communities defined as colonias [5]. Westway is home to about 4000 of these individuals. The population is $97 \%$ Hispanic and $45.5 \%$ are foreign-born, and of those foreign-born residents, only $22.2 \%$ are naturalized US citizens [6]. Westway is located next to Interstate 10, across the ArcelorMittal Vinton steel plant and proximate to other polluting industries such as a scrap metal recycling plant. In Westway, as in other colonia environments, a confluence of challenging socio-environmental conditions contributes to a difficult quality of life for residents and, as a consequence, the potential for high rates of mental health issues and barriers in coping with them. As such, we have two objectives: (1) characterize Westway residents' rates of mental health outcomes and access to mental health care and (2) assess intraethnic disparities (i.e., based on level of environmental concerns, nativity, language acculturation, comorbidities, gender, health insurance, and stressful life events) in mental health outcomes within this impoverished, Hispanic population.

\footnotetext{
${ }^{1}$ Officially, Westway is a collection of seven colonias (Westway $1-$ Westway 7; see http://www.sos.state.tx.us/border/colonias/reg-colonias/ elpaso-6.shtml), although residents treat it as one contiguous community.
} 


\section{Health and Environmental Concerns in Colonias}

Colonias tend to lack basic community infrastructure such as paved roads, sewer system, electricity, gas, clean water, and health care services $[1,3,7]$. The lack of infrastructure and poverty combines to foster the spread of diseases such as hepatitis, dysentery, and tuberculosis [1]. Poverty also leads to food insecurity and poor nutritional health, which can cause obesity and diabetes, which are common along the USMexico border [8]. Chronic illnesses, such as diabetes and asthma, are also prevalent in colonias [3].

Unsafe environmental conditions (e.g., presence of junk yards) have been linked with physical illness in colonias. Underdevelopment and the presence of empty lots sometimes leads both colonia residents and others to dispose of household and industrial wastes in the neighborhoods, creating physical health risks [9]. Ramos et al. [3] found that residents living closer to junk yards or dry cleaners in the Cameron Park colonia in east Texas had significantly higher risk of developing a respiratory illness than those living farther away.

In terms of mental health, the focus of this paper, Anders et al. [4] found high rates of mental illness in an El Paso County colonia (not Westway); $20 \%$ of adults had been diagnosed with depression and $17 \%$ had been diagnosed with anxiety. It may also be that the environmental conditions in colonias are correlated with chronic stress and psychological distress, which can permeate the physical and psychological well-being of individuals [10]. Downey and Van Willigen [11] argued that environmental stressors (as chronic stress sources) can have long-lasting effects on the psychological well-being of residents living in industrialized areas. While not studying colonias, Downey and Van Willigen [11] found that Illinois residents living near industrial activity reported higher depressive symptomatology, a greater sense of disorder, and more feelings of powerlessness than those not living close to industrial facilities. Similar findings relating environmental concerns to mental disorders were found in national-level datasets in Spain [12] and Portugal [13].

\section{Mental Health and Access to Care for Hispanics}

Given that colonia residents are Mexican-origin Hispanics, it is relevant to this study that Hispanics have lower rates of mental disorders than non-Hispanic whites [14]. Within the Hispanic population, there are disparities in mental health outcomes, based on three important characteristics: nativity, language acculturation, and chronic physical illness. In terms of nativity, immigrants tend to have lower rates of mental disorders than their US-born counterparts $[15,16]$. Hispanics that have acculturated to white middle-class norms are more prone to develop mental health disorders. For example, Englishspeaking Hispanics have higher rates of mental disorders [17] than Hispanics who are predominantly Spanish speaking.
Those suffering from chronic physical illnesses (e.g., diabetes) are more likely to develop a mental health condition [17]. This fact is concerning in Hispanic populations because they show an early onset and a high risk of developing conditions such as diabetes, kidney disease, and hypertension [18] which often co-occur with depression [19].

Even though Hispanics have lower rates of mental illness, the US Department of Health and Human Services has identified critical mental health disparities that apply to Hispanics, which include reduced access to mental health services, decreased likelihood to receive needed services, and poor quality treatment [20]. In terms of reduced access to needed services, foreign-born, primarily Spanish speaking, recent immigrant, first generation, and uninsured Hispanics showed the lowest rates of access to mental health services [21]. Hispanics who did not speak English received needed mental health services at lower rates than proficient English speakers [22]. Mexicanorigin people with mental health challenges have very low utilization rates for mental health services even when compared to other Hispanic subgroups, like Puerto Ricans [21]. The lack of access to quality care experienced by Hispanics makes them more prone to chronicity and higher levels of impairment due to mental illness [18]. Poor quality of care is reflected in the fact that Hispanics and other minorities' main source of mental health care is primary care physicians rather than specialists such as psychiatrists [22].

\section{Other Influences on Mental Health}

There are other influences on mental health besides the Hispanic ethnic features and industrial concerns previously discussed. These include gender, lack of health insurance, and stressful life events. In terms of gender, women have higher rates than men of major depressive disorder, anxiety disorders, posttraumatic stress disorder, and eating disorders in the United States [23]. Lack of insurance coverage is an important barrier when in need of mental health services, and it might cause a deferment of treatment. Finally, stressful life events (e.g., loss of loved one) are associated with poor mental health because these events can "lead to stress by adversely altering the meaning of persistent life strains" [24].

\section{Materials and Methods}

\section{Study Area}

Westway (see Fig. 1) is home to a low-income population: $49.2 \%$ live below the poverty line, $15.4 \%$ have an income of less than $\$ 10,000$ per year, and $35 \%$ received public assistance during the last 12 months. Only $55.4 \%$ of Westway residents are in the labor force, mainly in service occupations, sales, construction, maintenance, and transportation [6]. 


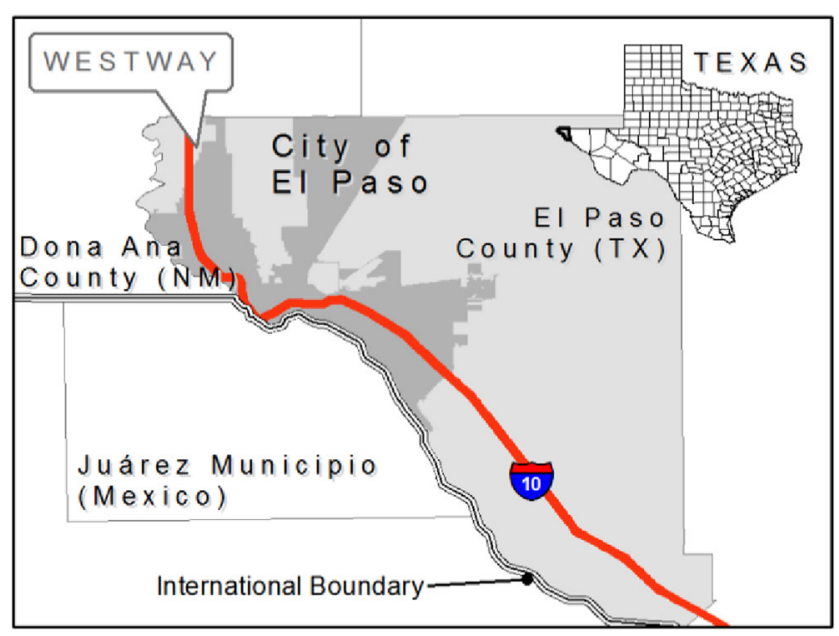

Fig. 1 Westway, Texas

Ninety-eight percent of residents are Hispanic and only $9.4 \%$ report speaking only English at home. Over $64.3 \%$ of Spanish speakers speak English less than very well [6]. For additional demographic information, see Table 1.

Westway residents are exposed to numerous environmental hazards. Just across Interstate 10 is the steel plant, which was built in 1962 and emits zinc, lead, and manganese into the air [25]. As such, the elementary school located in Westway was ranked in the second percentile nationally in terms of bad air

Table 1 Demographic characteristics of surveyed Westway residents $(N=98)$

\begin{tabular}{lll}
\hline Variable & Descriptive information & \\
\hline Age & Min & 18 \\
& Max & 80 \\
Gender & Feman & 47 \\
Years of education & Male & $57 \%$ \\
& Min & $43 \%$ \\
Occupation & Max & 0 \\
& Mean & 18 \\
& Professional & 10 \\
& Manufacturing & $5 \%$ \\
Time living in Westway & Service & $3 \%$ \\
& Transportation & $30 \%$ \\
Number of individuals & Construction & $4 \%$ \\
in the household & Retired & $13 \%$ \\
& Homemaking & $12 \%$ \\
& Min & 1 month \\
& Max & 52 years \\
& Mean & 18 years \\
& Min & 1 \\
& Max & 3.8 \\
\hline
\end{tabular}

quality in a 2009 report [26]. Strong seasonal winds in the area provoke dust storms that spread dust from unpaved roads and lots and contaminants from industry. Residents' concerns about the environment led them to request that a team of university researchers conduct a health screening survey in their community [27]; this paper reports some of the results from that effort.

\section{Data Collection and Participants}

The first author and an assistant collected the data through door-to-door surveying between March and August 2012. Every ninth household (out of the 1120 lot units in Westway) was asked to participate. If the residents were not home, the neighbors on the left side were asked to participate. We made contact with an adult over 18 at 127 households; 23 declined and one withdrew for an $81 \%$ response rate $(n=103)$. For the analysis, we excluded the one non-Hispanic respondent and four relatively affluent respondents (i.e., those earning more than the county per capita average for income ${ }^{2}$ ) for a final $N$ of 98 low-income respondents. The survey, translated by the first author and an assistant, both of whom are native speakers of Spanish, was offered in English and Spanish. The survey was designed by the research team through a community-based research process led by the third author. Community leaders were involved in the research process including making revisions and additions to the questionnaire. This study was approved by the Institutional Review Board at the authors' home institution.

\section{Measures and Analysis}

The first research objective involves descriptive statistics for a suite of mental health variables and access to care variables. The mental health outcomes include three sets of variables: diagnoses of specific conditions, psychological symptoms [28], and physical symptoms [29]. We utilized a physical symptomatology scale because Hispanics might tend to report physical symptoms in lieu of depression, anxiety, and/or stress [14]. Table 2 shows all variables used in the first research objective, along with information about the survey questions, coding, and descriptive statistics.

The second research objective involves correlation and regression analyses. Table 3 reports descriptive statistics and details for how the independent variables (i.e., industrial concerns, nativity, language acculturation, comorbidities, gender, health insurance, and stressful life events) were constructed. We used "industrial concerns" as our measure of environmental concern given the many industrial sources of pollution in

\footnotetext{
${ }^{2}$ As a point of reference, the Westway per capita mean in our sample was $\$ 6255$, the county mean was $\$ 18,086$, and the US mean is $\$ 28,051$ (ACS, 2008-2012).
} 


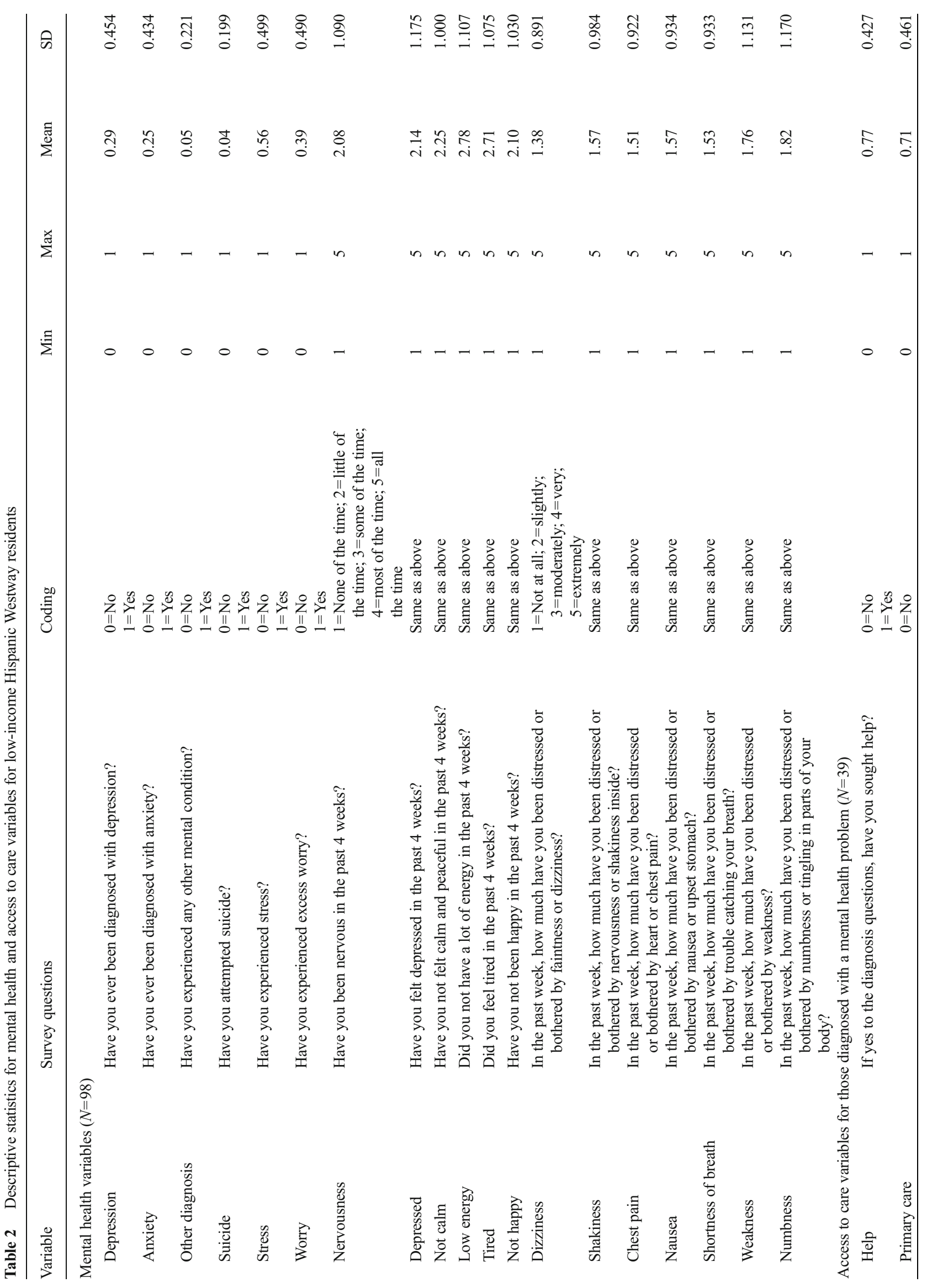


the neighborhood and our knowledge of residents' concern about these activities in their neighborhood.

Table 3 reports the same information for the four dependent variables. (1) "Mental health diagnosis" is coded 1, if the respondent said "yes" to a diagnosis of anxiety, depression, and/or another mental health illness; it is coded 0 if the person had none of those diagnoses. (2) "Stress and excess worry" is coded 1 if the respondent said "yes" to either or both of the questions about ever experiencing stress and ever experiencing excess worry and 0 if the person has never experienced either. (3) "Psychological symptoms in the last 4 weeks" was created by factor analyzing (Principal Axis Factoring) six Likert items (see Table 3). Descriptive statistics for the Likert items contained in this factor (and the next one) are included in Table 3, along with the component loadings. (4) "Physical symptoms in the last 1 week" was created by factor analyzing (PAF) seven Likert items (see Table 3).

After running bivariate correlations between the independent and dependent variables, we ran four regression models including the seven independent variables detailed in Table 3. We used binary logistic models for the dichotomous dependent variables and ordinary least squares (OLS) modes for the continuous dependent variables. Collinearity diagnostics [i.e., variance inflation factors (VIF) and tolerance] revealed that there were no issues with multicollinearity; all independent variables met the standard of a VIF below 2.9 and a tolerance value greater than 0.4 .

\section{Results}

Describing Mental Health Outcomes and Access to Care

One third of surveyed Hispanic residents have been diagnosed with depression and one quarter have been diagnosed with an anxiety disorder; $36 \%$ had been diagnosed with at least one of the following mental health issues: depression, anxiety, and posttraumatic stress disorder or had attempted suicide. Nearly $60 \%$ reported ever feeling stressed and excessively worried.

In terms of access to care for mental health issues (see Table 2), $77 \%$ of individuals with a diagnosed mental health condition have received health care for it. Of those receiving care for a diagnosed mental illness, $71 \%$ receive care from their primary care physician for their diagnosed condition and $56 \%$ take a medication. Only $7 \%$ have seen a specialist for their diagnosis and $17 \%$ have received a form of psychological therapy. More generally in the sample, $46 \%$ of all respondents did not have health insurance (see Table 3). Of the total respondents, $18.6 \%$ had insurance through their workplace, $20 \%$ had Medicare, and $7 \%$ had Medicaid. Eight percent had other forms of health insurance (e.g., Mexican health insurance) (not shown in a table). 


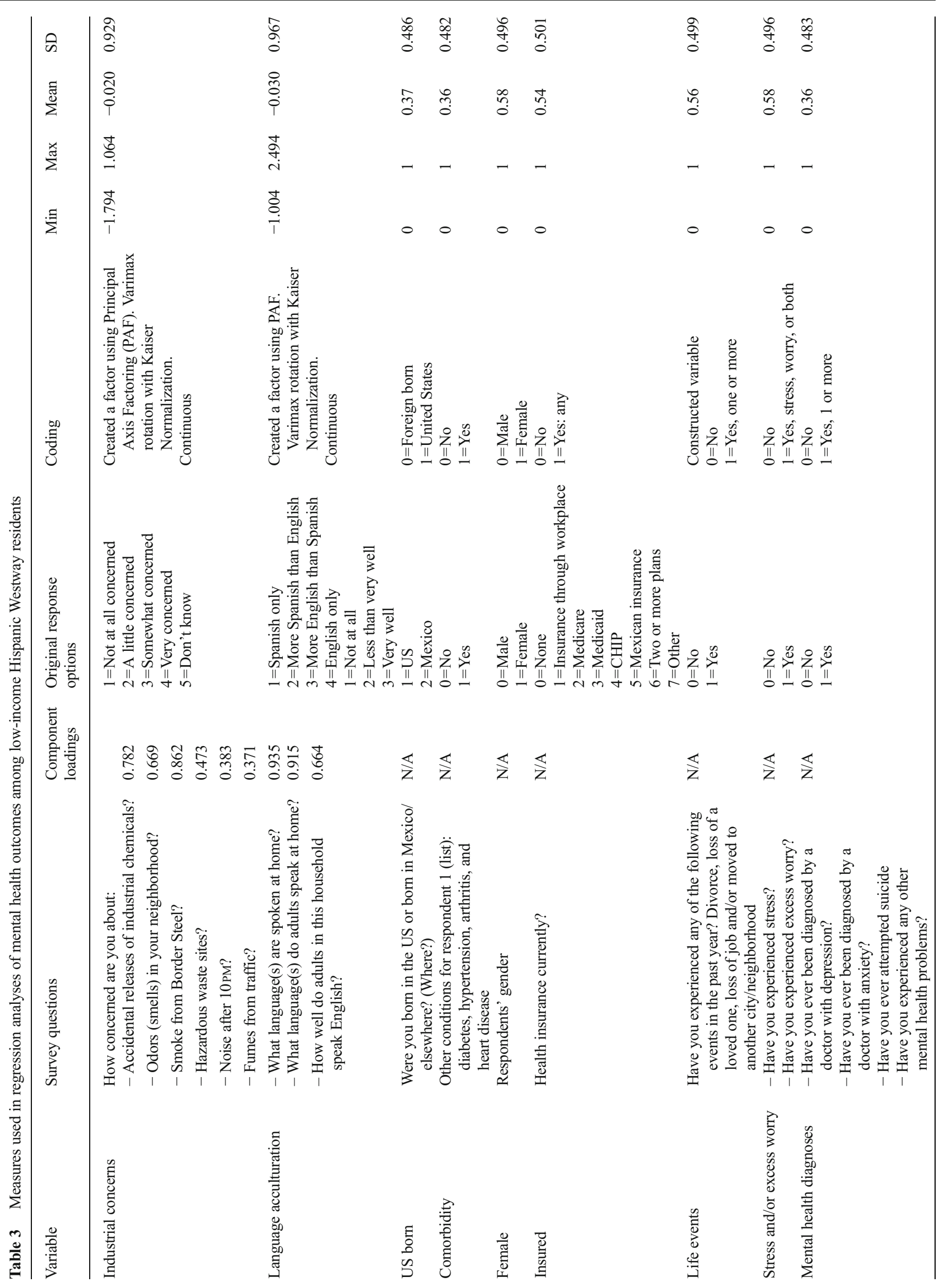




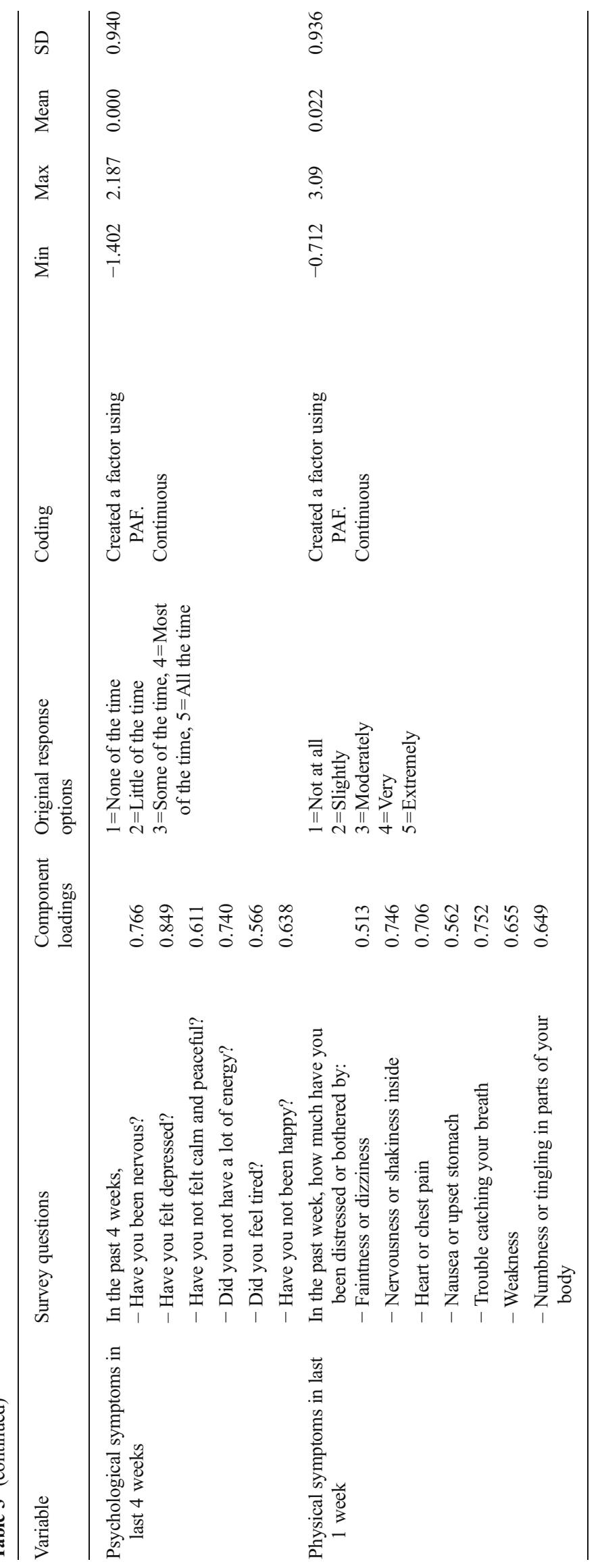




\section{Assessing Disparities in Mental Health Outcomes}

Table 4 presents the results from the correlational analysis between the independent and dependent variables. The following statistically significant correlations were found: Language acculturation was positively correlated with stress and excess worry. Comorbidity was positively correlated with diagnosis of mental health condition and psychological symptoms in the past 4 weeks. Being female was significantly correlated with all dependent variables. Having more stressful life events variable was positively correlated with the diagnosis variables as well as psychological and physical symptoms variables. Finally, industrial concerns were significantly correlated with stress and excess worry and psychological symptoms of distress in the past 4 weeks.

Table 5 presents results from the regression models. For the logistic model predicting stress and/or excess worry (Table 5, A), there were three significant $(p<0.05)$ findings and one finding that approached significance $(p<0.1)$. A one-unit increase in the language acculturation scale (which is 1 standard deviation) leads to a 2.5 times increase in the odds of a respondent experiencing stress and/or excess worry. Likewise, females are 2.6 times more likely to feel stressed and/or worried than males. Individuals with one or more comorbid conditions are 2.9 times more likely to experience stress and/or excess worry. A one-unit increase in the industrial concerns scale results in a 2.5 times increase in the odds of a respondent experiencing stress and/or worry. US-born individuals are 0.8 times less likely to experience stress and/or excess worry than foreign-born individuals.

For the logistic model predicting a diagnosis of a mental health condition (Table 5, B), there were two statistically significant $(p<0.05)$ findings. Females and those who experienced one or more life events in the past year are both 6.9 times more likely to be diagnosed with a mental illness.

For the OLS model predicting the respondent's psychological symptoms of distress in the last 4 weeks (see Table 5, C), four variables were significant at the $p<0.05$ level. For individuals with at least one comorbid condition, there is a 0.4 increase in the psychological symptoms scale. For females, there is an increase of 0.5 in the scale when compared to males and there is an increase of 0.7 for those who experienced one or more life events in the last year. A one-unit increase in the industrial concerns scale results in an increase of 0.255 in the psychological symptoms scale.

For the OLS model predicting the respondent's physical symptoms of distress in the last week (Table 5, D), there were three significant predictors $(p<0.05)$. Females had a score on

Table 4 Correlations between covariates and mental health outcomes for low-income Hispanic Westway residents

\begin{tabular}{|c|c|c|c|c|c|}
\hline & & $\begin{array}{l}\text { Stress and/or } \\
\text { excess worry }\end{array}$ & $\begin{array}{l}\text { Diagnosis of mental } \\
\text { health issues }\end{array}$ & $\begin{array}{l}\text { Psychological } \\
\text { symptoms in last } \\
4 \text { weeks }\end{array}$ & $\begin{array}{l}\text { Physical } \\
\text { symptoms } \\
\text { in last } 1 \text { week }\end{array}$ \\
\hline \multirow[t]{3}{*}{ English language acculturation } & Corr. & $0.245^{*}$ & 0.143 & 0.142 & -0.021 \\
\hline & Sig. & 0.015 & 0.163 & 0.173 & 0.838 \\
\hline & $N$ & 97 & 97 & 94 & 94 \\
\hline \multirow[t]{3}{*}{ Born in the United States } & Corr. & -0.137 & -0.133 & -0.120 & -0.086 \\
\hline & Sig. & 0.182 & 0.195 & 0.251 & 0.410 \\
\hline & $N$ & 97 & 97 & 94 & 94 \\
\hline \multirow[t]{3}{*}{ Comorbid conditions } & Corr. & 0.114 & $0.200^{*}$ & $0.245^{*}$ & 0.164 \\
\hline & Sig. & 0.263 & 0.048 & 0.017 & 0.113 \\
\hline & $N$ & 98 & 98 & 95 & 95 \\
\hline \multirow[t]{3}{*}{ Female } & Corr. & $0.245^{*}$ & $0.373^{* *}$ & $0.307^{* *}$ & $0.269^{* *}$ \\
\hline & Sig. & 0.015 & 0.000 & 0.002 & 0.009 \\
\hline & $N$ & 98 & 98 & 95 & 95 \\
\hline \multirow[t]{3}{*}{ Has insurance coverage } & Corr. & -0.149 & 0.010 & -0.084 & -0.083 \\
\hline & Sig. & 0.144 & 0.921 & 0.420 & 0.427 \\
\hline & $N$ & 97 & 97 & 94 & 94 \\
\hline \multirow{3}{*}{$\begin{array}{l}\text { Respondent has experienced } \\
\text { stressful life events }\end{array}$} & Corr. & 0.125 & $0.359^{* *}$ & $0.420^{* *}$ & $0.280^{* *}$ \\
\hline & Sig. & 0.218 & 0.000 & 0.000 & 0.006 \\
\hline & $N$ & 98 & 98 & 95 & 95 \\
\hline \multirow[t]{3}{*}{ Industrial related concerns } & Corr. & $0.271^{* *}$ & 0.152 & $0.218^{*}$ & 0.195 \\
\hline & Sig. & 0.008 & 0.144 & 0.038 & 0.064 \\
\hline & $N$ & 94 & 94 & 91 & 91 \\
\hline
\end{tabular}

*Correlation is significant at the 0.05 level (two-tailed), $* *$ correlation is significant at the 0.01 level (two-tailed) 
Table 5 Regression models predicting mental health outcomes for low-income Hispanic Westway residents

\begin{tabular}{|c|c|c|c|c|c|c|c|c|c|c|c|c|c|c|c|c|}
\hline & \multirow{2}{*}{\multicolumn{4}{|c|}{$\begin{array}{l}\text { A. Stress and/or excess } \\
\text { worry (logistic) } \\
\text { Nagelkerke } R^{2} 0.378\end{array}$}} & \multirow{2}{*}{\multicolumn{4}{|c|}{$\begin{array}{l}\text { B. Diagnosis of mental health } \\
\text { condition (logistic) } \\
\text { Nagelkerke } R^{2} 0.459\end{array}$}} & \multirow{2}{*}{\multicolumn{4}{|c|}{$\begin{array}{l}\text { C. Psychological symptoms in } \\
\text { last } 4 \text { weeks (OLS) } \\
\text { Adjusted } R^{2} 0.374\end{array}$}} & \multirow{2}{*}{\multicolumn{4}{|c|}{$\begin{array}{l}\text { D. Physical symptoms in last } \\
1 \text { week (OLS) } \\
\text { Adjusted } R^{2} 0.138\end{array}$}} \\
\hline & & & & & & & & & & & & & & & & \\
\hline & $B$ & $\mathrm{SE}$ & Sig. & $\operatorname{Exp}(B)$ & $B$ & SE & Sig. & $\operatorname{Exp}(B)$ & $B$ & SE & $t$ & Sig. & $B$ & SE & $t$ & Sig. \\
\hline $\begin{array}{l}\text { Language } \\
\text { acculturation }\end{array}$ & 0.905 & 0.325 & 0.005 & 2.471 & 0.518 & 0.321 & 0.107 & 1.679 & 0.135 & 0.091 & 1.495 & 0.139 & -0.020 & 0.106 & -.187 & 0.852 \\
\hline US born & -1.396 & 0.597 & 0.019 & 0.248 & -1.072 & 0.651 & 0.100 & 0.342 & -0.285 & 0.177 & -1.610 & 0.111 & -0.059 & 0.208 & -.282 & 0.779 \\
\hline Comorbidity & 1.054 & 0.607 & 0.083 & 2.868 & 1.001 & 0.609 & 0.100 & 2.721 & 0.447 & 0.178 & 2.521 & 0.014 & 0.228 & 0.214 & 1.066 & 0.290 \\
\hline Female & 0.941 & 0.525 & 0.073 & 2.562 & 1.942 & 0.619 & 0.002 & 6.973 & 0.522 & 0.162 & 3.225 & 0.002 & 0.475 & 0.194 & 2.453 & 0.016 \\
\hline Insured & -0.757 & 0.557 & 0.174 & 0.469 & 0.688 & 0.609 & 0.259 & 1.990 & -0.126 & 0.167 & -0.756 & 0.452 & -0.121 & 0.201 & -0.603 & 0.548 \\
\hline Life events & -0.112 & 0.536 & 0.835 & 0.894 & 1.941 & 0.622 & 0.002 & 6.964 & 0.675 & 0.164 & 4.127 & 0.000 & 0.414 & 0.194 & 2.127 & 0.037 \\
\hline $\begin{array}{l}\text { Industrial } \\
\text { concerns }\end{array}$ & 0.907 & 0.305 & 0.003 & 2.478 & 0.538 & 0.322 & 0.094 & 1.712 & 0.255 & 0.087 & 2.928 & 0.004 & 0.216 & 0.103 & 2.098 & 0.039 \\
\hline
\end{tabular}

the physical symptoms scale that was 0.5 higher than males and those who experienced a life event also had an increase of 0.4 in the scale. A one-unit increase in the industrial concerns scale resulted in a 0.2 increase in the physical symptoms scale.

\section{Discussion}

In terms of rates of mental health problems, Westway residents have rates of diagnosed depression (29\%) that were more than three times the rates for Texas residents $(9 \%)$ and the US population (7\%) in any given year [30,31]. Similarly, their anxiety rates $(25 \%)$ are higher than the national rate of $18 \%$ in any given year according to the National Institute of Mental Health $[32,33]$. Thirty-six percent of Westway residents report being diagnosed with at least one mental illness contrasting with the $18 \%$ of individuals over 18 with any mental illness in Texas and the $20 \%$ of people with any mental illness in the United States [33]. Locally, Westway residents also showed greater rates of diagnosed mental health conditions than the residents of the San Elizario colonias (also in El Paso County, Texas) as previously reported by Anders et al. [4]. They found a $20 \%$ depression rate and a $17 \%$ anxiety rate compared to our rates of 29 and $25 \%$, respectively. Elevated rates of mental illness in Westway are concerning because if left untreated or undertreated, they can create unnecessary disability and further the economic challenges faced by residents [34] exacerbating inequality.

Like the rest of the US population, most Westway residents diagnosed with a mental illness treat their conditions through primary care physicians. Seventy-one percent of those receiving care for depression or anxiety receive it from a primary care provider, which is slightly lower than the national statistics as $74 \%$ of Americans who seek help for depression go to a family doctor rather than a specialist [35]. Twenty-three percent of Westway residents have not received mental health care since their diagnosis of anxiety or depression. It is probable that a lack of health insurance is related to this lack of treatment. Westway residents' most proximate source of health care services is La Fe Clinic, which is located at the north edge of the community. The clinic is part of the Centro de Salud Familiar La Fe Inc., a non-profit organization dedicated to provide health care to underserved individuals in El Paso County. Residents of El Paso County can receive a variety of services at affordable prices from this clinic, which are determined on a sliding scale according to income. The clinic also accepts Medicare or Medicaid. However, La Fe does not have mental health specialists and psychiatry is not included in their list of specialty referrals according to their website. This likely contributes to the lack of specialty care observed among surveyed residents, given that we know that a good proportion of Westway residents, especially the uninsured and those with state-sponsored insurance coverage, use the $\mathrm{La} \mathrm{Fe}$ clinic for their health care needs.

The lack of access to specialty mental health care is a nationwide problem. At the local level, El Paso County has only 823 mental health professionals (and only 27 of these are psychiatrists), which is 107 for every 100,000 people [20]. In the state of Texas, only $34 \%$ of people with mental illnesses receive needed care. The situation is worse in Westway where only $7 \%$ of people with an anxiety or depression diagnosis have seen a specialist. Texas is the state with the least treatment dollars per capita of all states and its mental health care system has received a D grade $[36,37]$. The United States system also has a D grade. Nationwide, mental health care often lacks a focus on health and wellness; the data on mental health is inadequate and funding is scarce; the mental health workforce is not sufficiently maintained nor developed; and there is a deficiency in cultural competency among providers and a culture of disrespect for the mentally ill $[36,37]$. 
In terms of assessing intra-ethnic disparities in mental health outcomes, we found that Westway residents with higher levels of industrial concerns were significantly more likely to experience three of the four mental health outcomes tested here, and the fourth (diagnosis) approached statistical significance. While not the subject of many studies (see only 12-13), the relationship between industrial concerns and mental health problems has been found in diverse social groups ranging from the population of Spain [12] to Westway, Texas.

Westway residents have joined efforts with community organizations to address environmental issues in their community. They have participated with the Texas Industrial Areas Foundation (IAF) in El Paso to affect policy in a number of issues including environmental health. The newer IAF group in the region, Border Interfaith (BI), has worked with leaders in Westway to make the Texas Commission on Environmental Quality (TCEQ) aware of their environmental concerns. After several years of pressure, TCEQ has increased their oversight, albeit on a small scale (e.g., additional hours per year) of ArcelorMittal Vinton, one of the industries near Westway [27].

Counter to the literature [14-16], being born in the United States is associated with having less stress and excess worry $(p<0.05)$ and a lower likelihood of a mental illness diagnosis and fewer psychological symptoms in the last 4 weeks (both $p<0.10$ ) among this colonia population. However, previous studies [14-16] did not examine excess stress and worry specifically and instead focused on mental illness diagnoses. The association between being foreign-born and higher levels of stress and worry could be attributed to the fact that Westway is located near the US-Mexico border and that there are routinely law enforcement and border protection officials in the area. This police presence could cause stress and concern for foreign-born residents that are unauthorized to be in the United States [38]. Additionally, cartel violence occurring just across the border in Ciudad Juárez during the data collection may have contributed to stress and worry, especially for foreign-born residents, who likely maintained strong ties with relatives in Juárez. The strong presence of law enforcement officials and the cartel violence in Mexico as factors influencing foreign-born border residents to experience stress and worry while living in the US are hypotheses that should be investigated in future research.

We found that higher scores on the language acculturation scale predicted experiencing increased stress and excess worry $(p<0.05)$. This is surprising in light of the finding that foreign birth is a risk factor for stress and excess worry, although it aligns with the literature on the health-damaging effects of acculturation [17]. As expected, US-birth and language acculturation are correlated at 0.351 (table not shown). It means that holding constant the effect of nativity (and the other covariates), English speaking was associated with greater stress and excess worry. This reflects other studies finding that greater acculturation is associated with higher rates of mental illness [17]. In Westway, language acculturation approached statistical significance $(p<0.11)$ as a predictor of higher rates of actual diagnosed mental illness. In a study of mental health outcomes post-disaster in El Paso County, researchers also found that language acculturation was a risk factor for a mental health problem (i.e., experiencing depression or posttraumatic stress) post-flood among those whose homes were damaged [39].

Comorbidity was a significant predictor of psychological symptoms in the last 4 weeks, and it approached statistical significance for the stress/worry and diagnosis variables $(p<0.10)$, aligning with the strong relationship between chronic physical illness and mental disorders previously observed [18]. Given that Hispanics are at increased risk for these chronic conditions that commonly co-occur with depression, this finding is concerning from a public health perspective.

Being a female was a significant predictor $(p<0.05)$ of the diagnosis, psychological symptoms, and physical symptoms variables, and it approached significance for stress/worry $(p<0.10)$. This means that poor Hispanic women in this colonia, like women elsewhere, are more likely to experience mental health challenges [23]. Life events were also significant predictors $(p<0.05)$ of diagnosed mental illness, psychological symptoms, and physical symptoms of distress.

\section{Limitations}

The main limitation of this study is the small sample size $(N=$ 98 individuals in 98 different households), which is reflective of the small community under study ( $N=1120$ homes). A larger sample could allow for a more sophisticated statistical analysis. Secondly, the Center for Epidemiological StudiesDepression (CES-D) measure [40], which is one of the most widely used instruments to measure depressive disorders, was not used in this study, limiting its comparability. Third, while beyond the scope of this community-based participatory project, we did not collect information about when the person was diagnosed with their mental illness and his/her healthcareseeking experiences. Last, studies with Hispanics of more diverse backgrounds could also provide more information on how ethnicity impacts mental health outcomes.

\section{Relevance}

Despite the numerous challenges facing individuals in colonias, their mental health has remained understudied and unaddressed by policy makers and activists. Mental illnesses can be debilitating and they further risk for physical illness complications [41] and economic decline [34]. Hispanic residents of this colonia had high rates of mental health challenges and few resources to deal with them; residents' per capita 
income was one quarter of the US average and half lacked health insurance. As the Hispanic population in the US continues to grow, it is becoming increasingly important to understand the complexities of Hispanic health [39, 42]. This case study in a US colonia contributes to that goal by illustrating the health challenges and disparities present within this group of largely Mexican-origin, low-income Hispanics. Even within this socially marginalized group, mental health disparities were present with respect to environmental concerns, nativity, language acculturation, comorbidity, gender, and life events. These findings underscore the importance of considering intra-ethnic disparities in Hispanic health outcomes. The findings also highlight deficiencies in mental health care in the US, especially for low-income, peri-urban residents, such as those in Westway, and point to the need for increased access to mental health care at charity clinics serving poor populations.

Acknowledgments This work was jointly supported by the National Institute of Minority Health and Health Disparities (NIMHD) and the United States Environmental Protection Agency (Award Number P20 MD002287-05S1). The content is solely the responsibility of the authors and does not necessarily represent the official views of the NIMHD or the EPA. We acknowledge the assistance of Oscar Morales during the data collection phase of this project and Dr. Maria Cristina Morales during the statistical analysis. Residents of Westway participating in the project are also gratefully acknowledged.

Conflict of Interest Guadalupe Marquez-Velarde, Sara Grineski, and Kathleen Staudt declare that they have no conflict of interest.

Informed Consent All procedures followed were in accordance with the ethical standards of the responsible committee on human experimentation (institutional and national) and with the Helsinki Declaration of 1975, as revised in 2000 (5). Informed consent was obtained from all patients for being included in the study.

No animal studies were carried out by the authors for this article.

\section{References}

1. Parcher JW, Humberson DG. Using GIS to assess priorities of infrastructure and health needs of colonias along the United StatesMexico border. J Lat Am Geogr. 2009;8:129-48.

2. Davidhizar R, Bechtel DA. Health and quality of life within colonias settlements along the United States and Mexico border. Public Health Nurs. 1999;16:301-6.

3. Ramos IN, Baker Davis L, He Q, May M, Ramos KS. Environmental risk factors of disease in the Cameron Park colonia, a Hispanic community along the Texas-Mexico border. J Immigr Minor Health. 2008;10:345-51.

4. Anders RL, Olson T, Robinson K, Wiebe J, DiGregorio R, Guillermina $\mathrm{M}$, et al. A health survey of a colonia located on the West Texas, US/Mexico Border. J Immigr Minor Health. 2010;12: 361-9.

5. Grineski SE, Juárez-Carrillo PM. Environmental injustice in the USMexico border region. In: Lusk M, Staudt K, Moya E, editors. Social justice in the US-Mexico border region. London: Springer; 2012. p. 179-98.
6. U.S. Census Bureau. American Community Survey, 2008-2012 American Community Survey 5-Year Estimates, Tables DP02, DP03 and DP05 http://factfinder2.census.gov.

7. Staudt K. Free trade? Informal economies at the US-Mexico border. Philadelphia: Temple University Press; 1998.

8. Sharkey JR, Dean WR, Johnson CM. Association of household and community characteristics with adult and child food insecurity among Mexican-origin households in colonias along the TexasMexico border. Int J Equity Health. 2011;10:1-14.

9. Nuñez-Mchiri GG. Housing, colonias and social justice in the US Mexico border region. In: Lusk M, Staudt K, Moya E, editors. Social justice in the US-Mexico border region. London: Springer; 2012. p. 109-25.

10. Quinn K, Kaufman JS, Siddiqi A, Yeatts KB. Parent perceptions of neighborhood stressors are associated with general health and child respiratory health among low-income, urban families. J Asthma. 2010;47:281-9.

11. Downey L, Van Willigen M. Environmental stressors: the mental health impacts of living near industry activity. J Health Soc Behav. 2005;46:289-305.

12. Rocha K, Perez K, Rodriguez-Sanz M, Obiols JE, Borrell C. Perception of environmental problems and common mental disorders (CMD). Soc Psychiatry Psychiatr Epidemiol. 2012;47:1675-84.

13. Weir K. Smog in our brain: how air pollution affects our cognition and mental health. Monit Psychol. 2012;43:32-7.

14. Harris KM, Edlund MJ, Larson S. Racial and ethnic differences in the mental health problems and use of mental health care. Med Care. 2005;43:775-84.

15. Abe-Kim J, Takeuchi DT, Hong S, Zane N, Sue S, Spencer M, et al. Use of mental health-related services among immigrants and US born Asian Americans: results from the National Latino and Asian American study. Am J Public Health. 2007;97:91-8.

16. Alegria M, Canino G, Shrout PE, Woo M, Duan N, Vila D, et al. Prevalence of mental illnesses in immigrant and non-immigrant U.S. Latino groups. Am J Psychiatry. 2008;165:359-69.

17. Vega WA, Kolody B, Aguilar-Gaxiola S, Alderete E, Catalano R, Caraveo-Anduaga J. Lifetime prevalence of DSM III-R psychiatric disorders among urban and rural Mexican Americans in California. Arch Gen Psychiatry. 1998;55:771-8.

18. Le Cook B, McGuire TG, Alegria M, Normand S. Crowd-out and exposure effects of physical comorbidities on mental health care use: implications for racial-ethnic disparities in access. Health Serv Res. 2011;46:1259-80.

19. Jurkowski JM, Leckwan Westin E, Rossy-Millan J. Latina selfreported mental health and delay in health care in a new Latino destination. Women Health. 2010;50:213-28.

20. Villalobos G, Islas AA, et al. Mental health disparities and social justice in the US Mexico border region. In: Social justice in the US-Mexico border region. London: Springer; 2012. p. 145-59.

21. Alegria M, Mulvaney-Day N, Woo M, Torres M, Gao S, Oddo V. Correlates of past-year mental health service among Latinos: results from the National Latino and Asian American study. Am J Public Health. 2007;97:76-83.

22. Sentell T, Shumway M, Snowden L. Access to mental health treatment by English language proficiency and race/ethnicity. J Gen Intern Med. 2007;22:288-93.

23. Office of the Surgeon General, Surgeon General's Workshop on Women's Mental Health. http://www.ncbi.nlm.nih.gov/books/ NBK44650/. Accessed 22 April 2013.

24. Pearlin LI, Menaghan EG, Lieberman MA, Mullan JT. The stress process. J Health Soc Behav. 1981;22:337-56.

25. The Right-to-Know Network, Toxic Release Inventory. http://www. rtknet.org/db/tri/tri.php?zip $=79835 \% 25 \&$ county $=\mathrm{el}+$ paso\&state $=$ TX\&dbtype $=$ C\&corechem $=n \& r s e i=y \&$ sortp $=$ D\&reporting year $=$ 2012\&datype $=$ T\&reptype $=$ f\&database $=$ tri\&detail $=-1 \&$ submit $=$ GO . Accessed 28 July 2014. 
26. USA Today. The Smokestack Effect: Toxic Air and America's Schools. http://content.usatoday.com/news/nation/environment/ smokestack/search/TX/ / /deanna+davenport/name/ /1/ (2009). Accessed 10 June 2012.

27. Staudt K, Marquez-Velarde G, Dane'el M. Stories, science, and power in policy change: environmental health, community-based research, and community organizing in a U.S.-Mexico border colonia. Environ Justice. 2013;6:191-9.

28. de Heer HD, Balcazar HG, Morera OF, et al. Barriers to care and comorbidities along the US-Mexico border. Public Health Rep. 2013;128:480-8.

29. Hill TD, Ross CE, Angel RJ. Neighborhood disorder, psychophysiological distress and health. J Health Soc Behav. 2005;46:170-86.

30. Center for Disease Control. An estimated 1 in 10 U.S. adults report depression. http://www.cdc.gov/features/dsdepression/. Accessed 12 June 2013.

31. Center for Disease Control. Burden of mental illness. http://www.cdc. gov/mentalhealth/basics/burden.htm. Accessed 12 June 2013.

32. National Institute of Mental Health. The global cost of mental illness. http://www.nimh.nih.gov/about/director/2011/the-global-cost-ofmental-illness.shtml. Accessed 30 June 2013.

33. National Institute of Mental Health. The numbers count: mental disorders in America. http://www.nimh.nih.gov/health/publications/thenumbers-count-mental-disorders-in-america/index.shtml. Accessed 12 June 2013.

34. Insel TR. Assessing the economic costs of serious mental illness. Am J Psychiatry. 2008;165:663-5.
35. Mental Health America. Co-occurring disorders and depression. http://www.nmha.org/index.cfm?objectid=C7DF94C1-1372-4D20C8FE4E509C20471B. Accessed 12 June 2013.

36. National Association for Mental Illness Grading the States 2009: Texas. http://www.nami.org/Content/ContentGroups/Grading the States_20091/Texas_Grades09/NAMI_GTS09_TXnarrative.pdf. Accessed 22 April 2013.

37. National Association for Mental Illness. The state of public mental health services across the nation. http://www.nami.org/ gts Template09.cfm? Section=Findings \& Template $=/$ ContentManagement/ContentDisplay.cfm\&ContentID=75255. Accessed 12 June 2013.

38. Sabo S, Shaw S, Ingram M, et al. Everyday violence, structural racism and mistreatment at the US-Mexico border. Soc Sci Med. 2014;109:66-74.

39. Collins TW, Jimenez A, Grineski SE. Hispanic health disparities after a flood disaster: results of a population-based survey of individuals experiencing home site damage in El Paso (Texas, USA). J Immigr Minor Health. 2013;15:415-26.

40. Radloff LS. The CES-D scale: a self-report depression scale for research in the general population. Appl Psychol Meas. 1977;1:385401.

41. De Hert M, Correll CU, Bobes J, et al. Physical illness in patients with severe mental disorders: prevalence, impact of medications and disparities in health care. World Psychiatry. 2011;10:52-77.

42. Ortiz L, Arizmendi L, Cornelius LJ. Access to health care among Latinos of Mexican descent in colonias in two Texas counties. J Rural Health. 2004;20:246-52. 